\title{
Effects of 4-aminopyridine in myasthenia gravis
}

\author{
H. L U N D H, O. N I LSSON, A N D I R O É N \\ From the Departments of Neurology and Clinical Neurophysiology, University Hospital, \\ Lund, Sweden
}

SUMMARY A new drug, 4-aminopyridine, was prepared for use in humans and tested by repeated injections in six patients with myasthenia gravis. The drug caused improvement of muscle strength and neuromuscular transmission as demonstrated by clinical observations and repetitive electrical nerve stimulation. The drug was effective in cases without any other treatment as well as in cases undergoing treatment with anticholinesterases. It is concluded that 4-aminopyridine may be of value as a supplementary drug in the treatment of myasthenia gravis.

4-Aminopyridine (4-AP) strongly increases transmitter release from motor nerve terminals (Molgo et al., 1975; Vizi et al., 1977; Lundh, 1978), probably by affecting a voltage-dependent calcium permeability in the nerve terminal membrane, and thereby enhancing the influx of calcium ions during the nerve terminal action potential (Lundh and Thesleff, 1977). The drug has recently been shown to restore neuromuscular transmission in the myasthenic syndrome associated with bronchogenic carcinoma (Lundh et al., 1977b), and in paralysis produced by experimental botulinum toxin poisoning in the rat (Lundh et al., 1977a). Since 4-AP also enhances transmitter release from normal nerve terminals during repetitive nerve activity (Lundh, 1978), it might also be of value in the treatment of postsynaptic disorders of neuromuscular transmission such as myasthenia gravis. In this condition muscular weakness is believed to be caused by blockade of acetylcholine receptors by humoral antibodies (Grob, 1976).

\section{Patients}

The effects of 4-AP were tested by intravenous injections of the drug in repeated doses in six patients. All patients had characteristic clinical histories of myasthenia gravis and in all cases muscle power increased after edrophonium or neostigmine injections. At electrophysiological examination with repetitive nerve stimulation all patients showed responses compatible with the diagnosis of myasthenia gravis.

Address for correspondence and reprint requests: Dr $\mathbf{H}$. Lundh, Department of Neurology, University Hospital,S-22185 Lund, Sweden. Accepted 11 August 1978
CASE 1

This 20 year old woman (GR) experienced weakness of cranial nerve muscles and proximal limb muscles in 1970 at the age of 13 years. She recovered within one month but symptoms reappeared in 1976. When examined in November 1977 she suffered from pronounced facial weakness, ptosis, dysphagia and dysarthria, and weakness of the muscles of shoulder girdle and hands. The level of serum cholinergic receptor antibodies was 2.50 units $/ 1$ (normal $<0.20$ units $/ 1$ ). At the time of testing this patient had not yet received medical treatment. She was tested twice. On the first occasion only 4-AP was given. At the second test 4-AP was given after an initial injection of neostigmine. Particular effort was made in this case to document clinical as well as neurophysiological effects of the drug.

\section{CASE 2}

This 46 year old woman (SN) had suffered from myasthenia gravis since 1959. Her weakness affected particularly cranial and proximal limb muscles. She had been treated with anticholinesterases, ACTH, and prednisolone with clearcut although not persistent therapeutic effects. On two occasions she had been treated with artificial respiration because of respiratory muscle weakness. She had undergone thymectomy after which her condition improved for one year. She had also been given azathioprine for a few weeks before the test with no obvious effect. When tested in 1977 she was taking anticholinesterases, prednisolone, and azathioprine. Cholinergic receptor antibodies were not determined. 
CASE 3

This 53 year old man (FW), who since the autumn of 1976 had suffered from slowly progressive symptoms of muscle fatiguability of cranial muscles and girdle and proximal muscles of both upper and lower limbs, was admitted to hospital in November 1977. His muscle weakness was mild, and when tested he had received no medication. The serum level of cholinergic receptor antibodies was 0.50 units/1.

\section{CASE 4}

This woman (LS), aged 46 years had suffered from diplopia, dysphagia and weakness of neck muscles, and slight weakness of proximal limb muscles since 1974. Transcervical thymectomy was performed in 1975 with no effect on her clinical condition, and treatment with anticholinesterases and prednisolone caused only moderate improvement. In 1976 she underwent another operation with trans-sternal thoracotomy and removal of rests of thymic tissue. Postoperatively, the patient developed respiratory weakness and was treated with a respirator. After an ACTH intensive course followed by continuous prednisolone treatment for several months, her condition improved and only slight dysphagia and dysarthria remained. Titre of serum cholinergic receptor anti-bodies was 2.00 units $/ 1$. At the time of testing in October 1977 the patient was treated with anticholinesterases and prednisolone.

\section{CASE 5}

A 64 year old man (AG), who since April 1977 had suffered from dysarthria, diplopia, and ptosis, was shown by radiography to have a mediastinal tumour, which proved on biopsy to be a malignant thymoma. A thymectomy and postoperative radiotherapy produced no change in muscle power but the patient managed without medication. The test was performed in September 1977 at which time serum cholinergic receptor antibodies were 1.05 units/1.

\section{CASE 6}

This man (BJ), aged 39 years had experienced periods of slight dysphagia since 1973. In 1976 he developed dysarthria and weakness of proximal limb muscles. When admitted to hospital in 1977 symptoms had progressed moderately and he exhibited slight ptosis. Trans-sternal thymectomy produced clinical improvement, and the patient was without medication when tested. A blood sample contained no cholinergic receptor antibodies.

\section{Methods}

Different batches of 4-aminopyridine (Sigma Co, US) were identified by spectrophotometry and melting point measurements, and the batches were examined for purity by the determination of concentrations of inorganic salts and metals. Batches that passed the purity levels determined by Swedish National Medical Authorities (in Pharmacopea Nordica) were sterilised by millipore filtering, and the sulphate salt (see Lundh et al., 1977b) was prepared for human usage. The solutions used for injection were buffered to $\mathrm{pH} 7$. The injections were made by repeated doses (concentration $5 \mathrm{mg}$ / $\mathrm{ml}$ ) in the cubital vein or in a hand vein.

When performing the tests certain precautions for medical emergencies were taken. 4-Aminopyridine has a known analeptic effect (Lemeignan, $1970,1972,1973$ ), and in case 6 , who had a history of epileptic fits, the electroencephalogram was recorded continuously during the test. Recording of electrocardiogram, blood pressure, pulse rate, and respiratory rate were made repeatedly.

Ethical considerations were also taken into account. The project was accepted by an independent Ethics Committee of the hospital as well as by Swedish Government Medical Authorities. The patients participating in the tests gave their consent after objective information.

Conventional electrophysiological techniques were used to record the compound muscle action potential (CMAP) by surface electrodes on the thenar, hypothenar, deltoid, and infraorbital muscles during single and repetitive stimulation of the corresponding motor nerve at frequencies from 1 to 20 per second.

\section{Results}

\section{CLINICAL OBSERVATIONS}

Table 1 gives a summary of the effects of the drug on clinical test parameters in case 1 . The table shows that the administration of $10 \mathrm{mg}$ 4-AP sulphate within 10 minutes produced alleviation of muscular weakness comparable to that obtained after $0.5 \mathrm{mg}$ neostigmine. 4-AP acted on all muscles tested and, as indicated in the table, muscle weakness which was only slightly influenced by neostigmine similarly showed a weak response to 4-AP. After neostigmine injection the addition of 4-AP in some muscles (eyelids in case1) further improved muscle strength. However, in this investigation, we did not study whether 4-AP is able to improve muscle strength if the drug is added when anticholinesterases have produced their maximal effect. 
Table 1 Clinical parameters of muscle strength tested in case 1 before (control) and 10 minutes after intravenous injection of $4-A P(10 \mathrm{mg})$ and neostigmine $(0.5 \mathrm{mg})$ respectively. The table also describes the effects of the addition of 4-AP $(10 \mathrm{mg}) 10$ minutes after $0.5 \mathrm{mg}$ neostigmine

\begin{tabular}{|c|c|c|c|c|c|}
\hline & $\begin{array}{l}\text { Repetitive hand } \\
\text { dynamometer values* }\end{array}$ & $\begin{array}{l}\text { Maximum number } \\
\text { of repeated head } \\
\text { bends }\end{array}$ & Ptosis $\dagger$ (seconds) & $\begin{array}{l}\text { Strength of lower } \\
\text { facial muscles }\end{array}$ & Dysarthria \\
\hline & Right hand & & & \multirow{5}{*}{$\begin{array}{l}\text { Paralysis } \\
\text { Slight } \\
\text { improvement }\end{array}$} & \multirow{5}{*}{$\begin{array}{l}\text { Moderate } \\
\text { Slight }\end{array}$} \\
\hline \multirow{4}{*}{$\begin{array}{l}\text { Test } 1 \\
\text { control } \\
4-A P\end{array}$} & & & & & \\
\hline & $20,20,18,20$ & 12 & 22 & & \\
\hline & $35,30,30,35$ & 28 & 50 & & \\
\hline & Left hand & & & & \\
\hline \multirow{2}{*}{$\begin{array}{l}\text { Test } 2 \\
\text { control } \\
\text { Neostigmine }\end{array}$} & $30,30,35,30$ & 13 & 30 & \multirow{3}{*}{$\begin{array}{l}\text { Paralysis } \\
\text { Insignificant } \\
\text { improvement } \\
\text { Slight } \\
\text { improvement }\end{array}$} & Moderate \\
\hline & $50,50,45,45$ & 24 & 70 & & No \\
\hline Neostigmine +4 -AP & $50,55,55,55$ & 25 & $>180$ & & No \\
\hline
\end{tabular}

* Mean \pm SD in 10 healthy age-matched right handed women: right $74.3 \pm 12.0$, left $66.2 \pm 9.2$

$\dagger$ Time for upper lid to reach upper border of the pupil when gazing upwards.

In all the patients the intravenous injection of 10-20 mg 4-AP sulphate caused a marked improvement in clinical status. The other patients were not tested in such detail as case 1 , but case 4 reported disappearance of double vision, in case 5 difficulties in swallowing disappeared, and case 3 showed marked improvement in walking. Cases 2 and 6 reported general improvement of muscle strength, and hand dynamometer tests demonstrated doubling of test values.

\section{ADVERSE CLINICAL SIDE EFFECTS}

The intravenous injection of 4-AP in all patients within seconds caused paraesthesia periorally, which disappeared after a few minutes. After 4-AP injection four of the patients temporarily (half to two hours) experienced a sensation of unsteadiness during walking, but none of them showed objective signs of disturbed posture, gait, or coordination. Two patients, cases 1 and 3 , complained of anxiety and restlessness for a few hours after the injection. When the injection was made in a small vein in the hand or forearm the patients complained of deep aching pain in the arm of injection lasting for several hours. The patients' blood pressure and pulse frequency did not alter significantly after 4-AP injection.

\section{ELECTROPHYSIOLOGICAL OBSERVATIONS}

The electrophysiological observations before and 10-20 minutes after intravenous injections of 4-AP are summarised in Table 2 . Some improvement was found in all cases. The records from one of the tests are illustrated in the Figure. This patient (case 2), as well as cases 1 and 3 , showed a marked decrement of CMAP at low and moderately high stimulus frequencies, and little frequency poten- tiation after high frequency stimulation. Injection of 4-AP caused almost a normalisation of the decrement at 2 stimuli/second in case 2. (Figure, B as compared with G), and a considerable improvement at the other frequencies tested. For case 3 the decremental response in the infraorbital muscle was normalised, and in case 1 the decrements were reduced in infraorbital as well as the thenar muscles. Case 4 exhibited somewhat atypical electrophysiological results with a significant decrement only at relatively high stimulus frequencies (10-20 per second). A short lasting normalisation was observed after 4-AP in this case.

Two patients (cases 5 and 6) showed a marked frequency potentiation of the CMAP amplitude. In case 5, 4-AP caused an increase of the previously reduced CMAP amplitude, whereas the decremental response was not influenced. In case 6, 4-AP was tested when the patient was still under the influence of neostigmine and caused a further enhancement of the CMAP amplitude as well as a reduction of decrement. Also in case 1, 4-AP produced a further improvement of decrement in the infraorbital muscle in addition to the effect produced by neostigmine.

\section{Discussion}

Our results show that 4-AP is able to improve neuromuscular transmission in myasthenia gravis. The drug has a mechanism of action different from anticholinesterases, and it might improve the clinical status and neuromuscular transmission in patients already receiving optimal treatment with conventional drugs. It is possible that in the future 4-AP may be a valuable supplementary drug in the treatment of myasthenia gravis. Previous results in 
Table 2 Electrophysiological test parameters in the patients tested with 4-AP (10-20 mg intravenously). In $G R$ (case 1) test 2, and BJ (case 6) the effects of the addition of 4-AP after $0.5 \mathrm{mg}$ neostigmine are described. $C M A P=$ compound muscle action potential. Decrement=percentage decrease of $C M A P$ after four stimuli. Frequency potentiation=increase of CMAP after 10 seconds of maximal voluntary contraction

\begin{tabular}{|c|c|c|c|c|c|c|c|c|c|c|c|}
\hline \multicolumn{2}{|c|}{ Patient } & \multicolumn{5}{|c|}{ Before 4-AP } & \multicolumn{5}{|c|}{ After 4-AP } \\
\hline & & \multicolumn{2}{|c|}{$C M A P$} & \multicolumn{2}{|c|}{ Decrement } & \multirow{2}{*}{$\begin{array}{l}\text { Frequency } \\
\text { potentiation } \\
\%\end{array}$} & \multicolumn{2}{|c|}{$C M A P$} & \multicolumn{2}{|c|}{ Decrement } & \multirow{2}{*}{$\begin{array}{l}\text { Frequency } \\
\text { potentiation } \\
\%\end{array}$} \\
\hline & & $(m V)$ & (muscle) & $\%$ & $\begin{array}{l}\text { (stimulus } \\
\text { frequency) } \\
\text { per second }\end{array}$ & & $(m V)$ & (muscle) & $\%$ & $\begin{array}{l}\text { (stimulus } \\
\text { frequency) } \\
\text { per second }\end{array}$ & \\
\hline GR & 1 & $\begin{array}{l}5.4 \\
1.0 \\
\text { After } \\
6.4 \\
1.6\end{array}$ & $\begin{array}{l}\text { (thenar) } \\
\text { (infraorbital } \\
\text { stigmine } \\
\text { (thenar) } \\
\text { (infraorbital) }\end{array}$ & $\begin{array}{l}33 \\
64 \\
\\
18 \\
37\end{array}$ & $\begin{array}{l}(4) \\
(4) \\
(4) \\
(4)\end{array}$ & $\begin{array}{l}16 \\
- \\
-\end{array}$ & $\begin{array}{l}6.6 \\
1.6\end{array}$ & $\begin{array}{l}\text { (thenar) } \\
\text { (infraorbital) }\end{array}$ & $\begin{array}{r}20 \\
0\end{array}$ & $\begin{array}{l}(4) \\
(4)\end{array}$ & - \\
\hline GR & 2 & $\begin{array}{l}6.4 \\
1.0\end{array}$ & $\begin{array}{l}\text { (thenar) } \\
\text { (infraorbital) }\end{array}$ & $\begin{array}{l}36 \\
40\end{array}$ & $\begin{array}{l}(4) \\
(4)\end{array}$ & 16 & $\begin{array}{l}7.3 \\
1.4\end{array}$ & $\begin{array}{l}\text { (thenar) } \\
\text { (infraorbital) }\end{array}$ & $\begin{array}{l}25 \\
23\end{array}$ & $\begin{array}{l}(4) \\
(4)\end{array}$ & - \\
\hline SN & & 9.2 & (thenar) & 41 & (2) & 0 & 9.8 & (thenar) & 6 & $(2)$ & - \\
\hline FW & & $\begin{array}{l}7.5 \\
1.3\end{array}$ & $\begin{array}{l}\text { (thenar) } \\
\text { (infraorbital) }\end{array}$ & $30^{5-17}$ & $\begin{array}{l}(2) \\
(2)\end{array}$ & 10 & $\overline{1.35}$ & $\overline{\text { (infraorbital) }}$ & 0 & $(2)$ & - \\
\hline LS & & $\begin{array}{l}7.3 \\
6.4\end{array}$ & $\begin{array}{l}\text { (thenar) } \\
\text { (deltoid) }\end{array}$ & $\begin{array}{r}13 \\
7\end{array}$ & $\begin{array}{r}(20) \\
(4)\end{array}$ & 10 & $\begin{array}{l}8.2 \\
6.4\end{array}$ & $\begin{array}{l}\text { (thenar) } \\
\text { (deltoid) }\end{array}$ & $\begin{array}{l}0 \\
0\end{array}$ & $\begin{array}{r}(20) \\
(4)\end{array}$ & - \\
\hline $\mathrm{AG}$ & & 3.9 & (thenar) & 17 & (2) & 75 & 5.7 & (thenar) & 19 & (2) & 30 \\
\hline BJ & & $\begin{array}{l}7.4 \\
\text { After } \\
9.0\end{array}$ & $\begin{array}{l}\text { (thenar) } \\
\text { stigmine } \\
\text { (thenar) }\end{array}$ & $\begin{array}{l}24 \\
17\end{array}$ & $\begin{array}{l}\text { (2) } \\
\text { (2) }\end{array}$ & $\begin{array}{l}46 \\
50\end{array}$ & 10.3 & (thenar) & 9 & (2) & 43 \\
\hline
\end{tabular}

S. $\mathbf{N}$.

CMAP - thenar

Stim/s
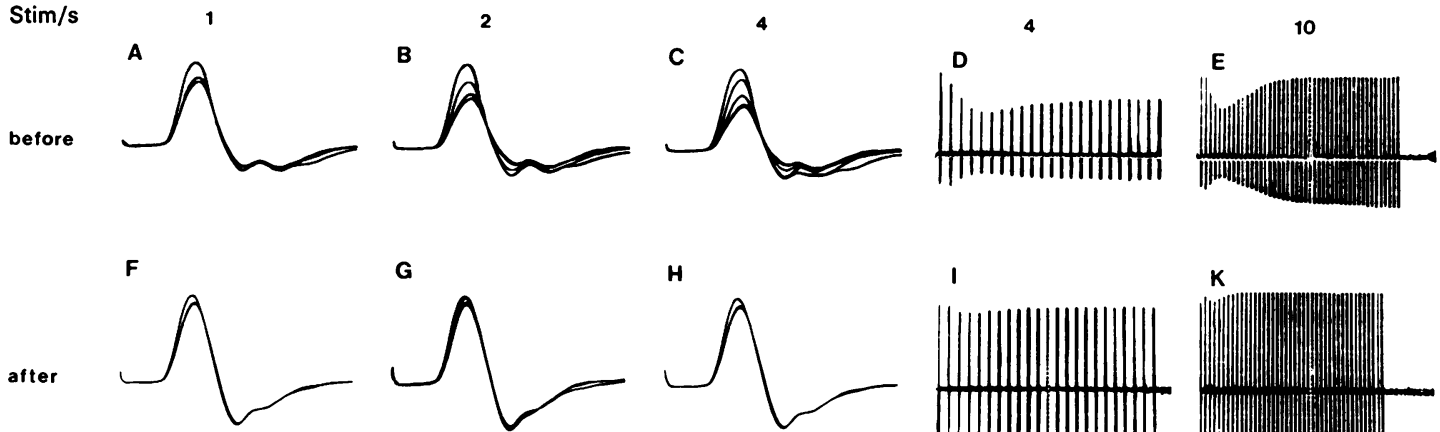

G
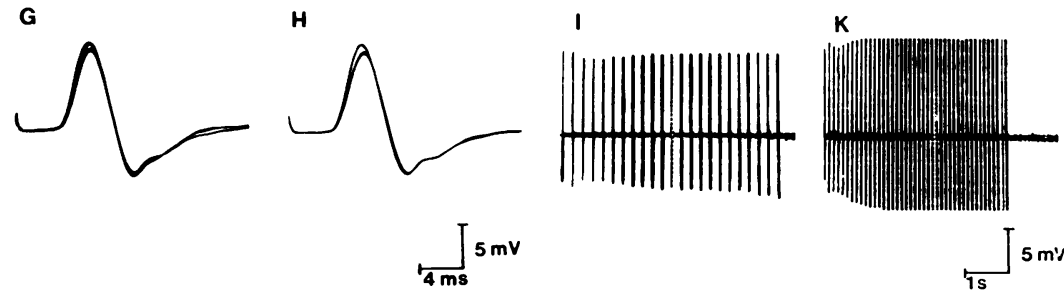

4-A-P

$$
55 \mathrm{mv}
$$$$
\text { is } 5 \mathrm{~mm}
$$

Figure Records of compound muscle act:on potentials (CMAPs) from the right thenar muscles on electrical suprathreshold stimulation of the median nerve in the forearm before $(A-E)$ and after $(F-K)$ $15 \mathrm{mg}$ of 4-AP given intravenously. Case $2(S N)$. The drug was given in three doses of $5 \mathrm{mg}$ each. The records $F-K$ were taken four minutes after the third injection and 20 minutes after the first one. Stimulus frequencies, time, and voltage calibrations are given in the figure.

the Eaton-Lambert syndrome (Lundh et al., 1977b) have demonstrated that the drug is active when given continuously orally.

The adverse side effects observed after injection of 4-AP included subjective instability on walking, anxiety, and perioral paraesthesia. 4-AP has previously been reported to cause photophobia (Lundh et al., 1977b), and produces ataxia in patients with senile dementia (unpublished). The side effects may be caused by actions on the central nervous system, since 4-AP is known to stimulate powerfully reflex activity and synaptic transmission in the brain and spinal cord (Lemeignan, 1970, 1972, 1973; Jankowska et al., 1977). These adverse effects may limit the usefulness of 4-AP in the treatment of neuromuscular disorders, but it may 
be possible to combine 4-AP in a dose not producing side effects with anticholinesterase medication. Sensitivity to side effects also seems to differ between individuals.

In myasthenia gravis the neuromuscular block is assumed to be postsynaptic and caused by decreased acetylcholine sensitivity of the muscle membrane (Grob, 1976). It is not known if transmitter release in myasthenia gravis is normal, but studies on the release process in this disease have demonstrated normal or increased quantum content of endplate potentials (Elmqvist et al., 1964; Cull-Candy et al., 1978). If the reduction of miniature endplate potential amplitude observed in this disease (Elmqvist et al., 1964) is caused by postsynaptic blockade of the acetylcholine receptors, it is, therefore, reasonable to assume that, in general, transmitter release in myasthenia gravis is not reduced. A-AP acts by increasing transmitter release from nerve terminals, and in paralysis caused by reduced transmitter release like botulinum toxin poisoning (Lundh et al., 1977a) and the Eaton-Lambert syndrome (Lundh et al., 1977b) the drug powerfully increases the amount of transmitter released by each nerve impulse during tetanic nerve activity and restores neuromuscular transmission. In conditions in which transmitter release is normal, A-AP is less potent but still markedly enhances transmitter release during repetitive nerve activity at frequencies below 50 per second (Lundh, 1978). This may explain the improvement of neuromuscular transmission produced by 4-AP in myasthenia gravis.

The observation of a marked enhancement of the CMAP by 4-AP in some patients with clinical myasthenia gravis is compatible with a postsynaptic blockade of neuromuscular transmission. However, its combination with a marked frequency potentiation after maximal voluntary contraction implies that these patients may have a presynaptic neuromuscular block in addition to the postsynaptic defect.

This study was supported by a grant from the Medical Faculty, University of Lund, Sweden.

\section{References}

Cull-Candy, S. G., Miledi, R., and Trautmann, A. (1978). Acetylcholine-induced channels and transmitter release at human endplates. Nature, 271, 74-75.

Elmqvist, D., Hofmann, W. W., Kugelberg, J., and Quastel, D. M. J. (1964). An electrophysiological investigation of neuromuscular transmission in myasthenia gravis. Journal of Physiology, 174, 417434.

Grob, D. (Editor) (1976). Myasthenia gravis. Annals of the New York Academy of Sciences, 274.

Jankowska, E., Lundberg, A., Rudomin, P., and Sykova, E. (1977). Effects of 4-aminopyridine on transmission in excitatory and inhibitory synapses in the spinal cord. Brain Research, 136, 387-392.

Lemeignan, M. (1970). Etude du mécanisme de l'action convulsivante de l'amino-4 pyridine. Thèse d'Etat, Faculté des Sciences de Paris.

Lemeignan, M. (1972). Analysis of the action of 4-aminopyridine on the cat lumbar spinal cord. I. Modification of the afferent volley, the monosynaptic discharge amplitude and the polysynaptic evoked responses. Neuropharmacology, 11, 551-558.

Lemeignan, M. (1973). Analysis of the effects of 4-aminopyridine on the lumbar spinal cord of the cat. II. Modifications of certain spinal inhibitory phenomena, post-tetanic potentiation and dorsal root potentials. Neuropharmacology, 12, 641-651.

Lundh, H. (1978). Effects of 4-aminopyridine on neuromuscular transmission. Brain Research, 153, 307318.

Lundh, H., Leander, S., and Thesleff, S. (1977a). Antagonism of the paralysis produced by botulinum toxin in the rat. Journal of the Neurological Sciences, 32, 29-43.

Lundh, H., Nilsson, O., and Rosén, I. (1977b). 4Aminopyridine - a new drug tested in the treatment of Eaton-Lambert syndrome. Journal of Neurology, Neurosurgery, and Psychiatry, 40, 1109-1112.

Lundh, H., and Thesleff, S. (1977). The mode of action of 4-aminopyridine and guanidine on transmitter release from motor nerve terminals. European Journal of Pharmacology, 42, 411-412.

Molgo, M. J., Lemeignan, M., and Lechat, P. (1975). Modifications de la libération du transmetteur à la jonction neuromusculaire de grenouille sous l'action del l'amino-4 pyridine. Comptes Rendus de'l Académie des Sciences Paris, Série D, 281, 1637-1639.

Vizi, E. S., van Dijk, J., and Foldes, F. F. (1977). The effect of 4-aminopyridine on acetylcholine release. Journal of Neural Transmission, 41, 265-274. 